\title{
Gestão estratégica de custos: Estudos de casos em empresas industriais do setor de construção naval localizadas no estado do Rio de Janeiro
}

\author{
Helmut Alexandre de Paula \\ Mestrado em Ciências Contábeis pela Universidade do Estado do Rio de \\ Janeiro - UERJ \\ Professor do Centro Universitário Anhanguera de Niterói - UNIAN \\ Av. Visconde do Rio Branco, 137. Centro. Niterói/RJ. CEP: 24020-000 \\ E-mail: helmut_de_paula@hotmail.com \\ Josir Simeone Gomes \\ Doutorado em Administração pela Universidade do Estado do Rio de Janeiro - \\ UFRJ \\ Universidade do Grande Rio - UNIGRANRIO \\ Rua da Lapa, 86. Centro. Rio de Janeiro/RJ. CEP: 25318-804 \\ E-mail: josirgomes@superig.com
}

\section{RESUMO}

O objetivo da pesquisa foi investigar as características dos sistemas de custos e qual uso as empresas da indústria de construção naval do Estado do Rio de Janeiro estão dando às informações de custos, para dar suporte à gestão estratégica. Procurando investigar aspectos relativos a esta prática, tem-se como propósito verificar a aplicação da teoria no setor. Para isso, foram realizados estudos de casos em cinco empresas da indústria de construção naval, onde foi realizada a coleta documental por meio da pesquisa bibliográfica. Para coleta de dados das empresas, foi aplicado um questionário por meio de entrevista pessoal conduzida pelo próprio pesquisador, às empresas estudadas, que constituem uma amostra não probabilística, ou seja, amostra por acessibilidade. $O$ estudo constatou que embora as empresas estudadas não fazem uso do $A B C$ com método de custeio, o que contraria o que é recomendando pela literatura, é dada uma especial atenção nas transações ocorridas ao longo da cadeia de valor, o que permite gerir os custos de maneira eficiente. Isso mostra a proximidade de diversas ações tomadas pelas empresas estudadas e a literatura sobre gestão estratégica de custos.

Palavras-chaves: Custos. Construção naval. Gestão estratégica de custos.

Strategic cost management: Case study of industrial companies in the naval industry located in the state of Rio de Janeiro 
Gestão estratégica de custos: Estudos de casos de empresas industriais do setor de construção naval localizadas no estado do Rio de Janeiro Helmut Alexandre De Paula, Josir Simeone Gomes

\section{ABSTRACT}

The objective of this research was to investigate the characteristics of cost systems of shipbuilding industry in Rio de Janeiro state are giving cost information to support strategic management. Looking investigate aspects of this practice, it has the purpose to verify the application of theory in the sector. For this, case studies were conducted in five companies in the shipbuilding industry, where he held the documentary collection through literature and corporate data collection was a questionnaire by personal interview conducted by the researcher, the companies studied constitute a non-random sample, namely sample accessibility. The study found that although the companies surveyed do not use $A B C$ with costing method which is contrary to what is recommended in the literature, special attention in the transactions is given occurring along the value chain, which allows you to manage the way costs efficient. This shows the proximity of various actions taken by the companies studied and the literature on strategic cost management.

Key words: Cost. Shipbuilding. Strategic cost management.

\section{INTRODUÇÃO}

O mercado globalizado, os constantes avanços tecnológicos, o aumento da concorrência e outros fatores têm alertado as empresas para a adoção de novas filosofias de gestão empresarial, o que exige uma busca constante pelo controle e gerenciamento dos custos, considerados como um diferencial competitivo para as empresas (REIS et al., 1998).

As empresas buscam um sistema de gestão de custos que atenda às necessidades gerenciais tanto do ambiente interno, como também no ambiente externo, pois a preocupação agora está em toda cadeia de valor, que tem início desde a aquisição de recursos materiais, financeiros e humanos, até o consumidor final (QUESADO; RODRIGUES, 2005).

O foco deixa de ser apenas os custos internos, ou seja, os ocorridos dentro da empresa. É essencial também conhecer os custos de seus fornecedores e dos clientes, para que seja possível se identificar ao longo de toda a cadeia de valor onde estão as chances de redução de custos que proporcionará vantagem competitiva. Conforme 
Gestão estratégica de custos: Estudos de casos de empresas industriais do setor de construção naval localizadas no estado do Rio de Janeiro Helmut Alexandre De Paula, Josir Simeone Gomes

afirma Porter (2004), as organizações buscam métodos (estratégias) para superar os concorrentes podendo elas optar pela liderança em custos, diferenciação e enfoque.

Diante de uma economia globalizada com acirrada concorrência, torna-se cada vez mais necessária a realização de estudos e pesquisas que possam colaborar com a implantação de práticas que auxiliem as organizações na definição de estratégias que sirvam de meio na superação da concorrência. O estudo traz à tona a importância da contabilidade no processo de gestão empresarial. Sendo assim, deverá a empresa dispor de informações necessárias ao processo de gestão, visando a utilização das melhores técnicas para obtenção de vantagem competitiva.

Apesar da necessidade das empresas por estas informações de custos, não se encontram na literatura estudos empíricos que tenham apresentado resultados relacionados à gestão estratégica de custos (GEC) na indústria de construção naval, e é com base nessa preocupação que o presente trabalho pretende responder ao seguinte questionamento: As empresas do segmento de construção naval do estado do Rio de Janeiro estão fazendo uso das técnicas de gestão estratégica de custos recomendadas pela literatura?

Cabe aqui mencionar alguns resultados obtidos por outros pesquisadores a respeito da GEC.

Carr e Tomkins (1996) realizaram uma pesquisa em 51 empresas da GrãBretanha e Alemanha (incluindo filiais das empresas nos EUA). A pesquisa aponta diferenças substanciais existentes entre os países, chamando atenção para as empresas alemãs, pois estas dedicam maior atenção às questões estratégicas.

Lord (1996), através de um estudo de caso, fez uma análise crítica sobre a GEC. O estudo verificou a relação entre o sistema de contabilidade e a gestão estratégica da empresa. O estudo observou que a exploração das ligações dentro da cadeia de valor proporciona vantagem competitiva. Porém, o autor ressalta que o resultado encontrado teve por base o estudo de uma empresa que fabrica um único produto e que o resultado encontrado não pode ser generalizado.

Araújo (2001) através de um estudo de campo em 8 empresas do setor hoteleiro em 6 estados brasileiros. Os resultados da pesquisa evidenciaram que as informações 
Gestão estratégica de custos: Estudos de casos de empresas industriais do setor de construção naval localizadas no estado do Rio de Janeiro Helmut Alexandre De Paula, Josir Simeone Gomes

geradas pelos sistemas de contabilidade, principalmente as informações de custos, têm se revelado de grande relevância para o processo de gestão estratégica de custos.

Roslender e Hart (2003) realizaram uma pesquisa em 10 empresas britânicas de segmentos e portes diferentes. A pesquisa teve como objetivo verificar a relação entre as técnicas de custos e a gestão estratégica e de marketing. A pesquisa ganhou relevância em função da exaustiva análise das práticas e à diversificação das empresas. A pesquisa verificou que o termo gestão estratégica de custos possuía um sentido restrito para a grande parte dos profissionais entrevistados.

\section{REVISÃO DA LITERATURA}

Nesta seção são descritas as bases da gestão estratégica de custos.

\subsection{A gestão estratégica de custos}

Os sistemas tradicionais (métodos) de custeio já não atendiam adequadamente às necessidades atuais de administração e controle, e foi em função dessa nova necessidade que surgiu a gestão estratégica de custos para preencher a lacuna deixada pelos sistemas tradicionais no que se refere a informações úteis ao processo estratégico (NAKAGAWA, 1991). Enquanto os sistemas tradicionais justificam as causas dos custos apenas em função do nível de atividade, a gestão estratégica de custos (GEC) ultrapassa os limites internos da empresa para gerenciar os custos ao longo de toda a cadeia de valor (SHANK e GOVINDARAJAM, 1997).

A GEC é aplicada tanto no enfoque interno como externo à organização. No enfoque interno, ela está voltada para estrutura de custos e seu ambiente operacional, buscando o alcance da excelência empresarial através da redução/eliminação de desperdícios. Com relação ao enfoque externo, a GEC, ao romper os limites do ambiente interno, amplia as possibilidades de maior agregação de valor ao estabelecer uma relação operacional e estratégica com o ambiente externo (PARISI; MEGLIORINI, 2011). A GEC compreende um conjunto de técnicas executadas pela contabilidade de custos no sentido de orientar a organização de forma estratégica (CADEZ; GUILDING, 2008). 
Gestão estratégica de custos: Estudos de casos de empresas industriais do setor de construção naval localizadas no estado do Rio de Janeiro Helmut Alexandre De Paula, Josir Simeone Gomes

[...] apesar de algumas empresas estarem preocupadas com a gestão de seus custos, a maioria continua considerando o volume de produção como a causa que melhor explica a variação dos custos e utiliza a classificação de custos fixos e variáveis, o ponto de equilíbrio e o custo marginal como ferramentas para a tomada de decisões gerenciais (CORRÊA; CANON, 2002, p. 202).

Desta forma, os sistemas tradicionais (métodos de custeio tradicionais) não analisam as entradas e saídas que ocorrem ao longo da cadeia de valor. Deixam de considerar, por exemplo, que possa ter ocorrido uma otimização do preço dos insumos adquiridos, e dependendo do segmento no qual a empresa esteja inserida, os custos dos insumos adquiridos poderão ter participação significativa no custo total. É por este motivo que se faz necessário analisar todos os elos da cadeia de valor e, assim, identificar onde poderão estar às chances de redução de custos, não ficando a empresa limitada a concentrar seus esforços de redução de custos nos aspectos relacionados à transformação, na qual a empresa efetivamente agrega valor ao produto (MARTINS, 2001).

Além das falhas encontradas nos sistemas tradicionais, o ambiente de negócios sofreu uma grande transformação, em função dos avanços tecnológicos que permitiram a automatização de grande parte dos processos produtivos e, ainda, à mudança no perfil do consumidor que passou a ser exigente no que diz respeito à qualidade dos produtos adquiridos. De acordo com Shank e Govindarajan (1997), a GEC possui como pilar a análise de três elementos, que são: a cadeia de valor, o posicionamento estratégico e os direcionadores de custos.

\subsubsection{A análise da cadeia de valores}

Para atuar com eficiência no atual cenário de competição é necessário gerenciar os custos com eficácia exigindo das organizações um enfoque amplo, externo à empresa. Sendo assim, os horizontes da análise de custos agora não se limitam apenas ao ambiente interno das organizações, mas também, ao longo de toda a cadeia de valor. A cadeia de valor é "o conjunto de atividades criadoras de valor desde as fontes de matérias-primas básicas, passando por fornecedores de componentes até o 
Gestão estratégica de custos: Estudos de casos de empresas industriais do setor de construção naval localizadas no estado do Rio de Janeiro Helmut Alexandre De Paula, Josir Simeone Gomes

produto final entregue nas mãos do consumidor". (SHANK; GOVINDARAJAM, 1997, p. 14).

De acordo com essa ótica, o enfoque passa a ser externo à empresa, na qual a análise é feita na cadeia global de atividades geradoras de valor para empresa, da qual ela é apenas uma parte, e que tem início nos fornecedores de matéria-prima e termina no consumidor final. Shank e Govindarajam (1997, p. 60) ainda comentam "[...] que as conclusões obtidas por meio de uma análise da cadeia de valor são muito diferentes - e superiores - às conclusões sugeridas pela convencional análise de valor agregado". A análise da cadeia dentro de uma perspectiva estratégica destaca quatro áreas de melhoria dos lucros: a) Ligações com fornecedores; b) Ligações com os clientes; c) Ligações de processo dentro da cadeia de valor de uma unidade empresarial; c) Ligações através das cadeias de valor da unidade empresarial dentro da empresa (SHANK; GOVINDARAJAM, 1997).

Para Maher (2001, p.47), "[...] a utilização da cadeia de valor e de informações sobre o custo das atividades ajuda as empresas a identificarem vantagens estratégicas no mercado em que atuam". De acordo com o autor, ao se conhecer a cadeia de valor e o custo das atividades, a empresa poderá identificar, ao longo da cadeia de valor, aquelas atividades que não agregam qualquer tipo de valor ao produto ou serviço e eliminá-las: desta forma, os custos poderão ser reduzidos sem a redução no valor do produto para os clientes.

Nesse sentido Quesado e Rodrigues (2005, p. 4) afirmam que:

Torna-se, então, necessário complementar a visão interna da empresa com informações sobre o ambiente externo, de forma a melhorar o desempenho global do negócio, compreendendo o impacto que as decisões estratégicas dos fornecedores e/ou clientes têm nas decisões da própria empresa.

Neste mesmo sentido, Parisi e Megliorini (2011, p. 261) argumentam que: "A análise global da cadeia de valor procura investigar possibilidades de tornar o produto final o menos dispendioso possível para o último consumidor, o que viabiliza a vantagem competitiva em todos os elos dessa cadeia". Os autores ainda comentam que 
Gestão estratégica de custos: Estudos de casos de empresas industriais do setor de construção naval localizadas no estado do Rio de Janeiro Helmut Alexandre De Paula, Josir Simeone Gomes

a análise deve ser dividida em duas partes: 1) análise da cadeia de valor interna e 2) análise da cadeia de valor externa. De maneira semelhante, Aguiar e Martins (2006) destacam a importância da cadeia de valor no processo de gestão estratégica de custos, e que aquela possui duas dimensões: interna e externa. A integração entre as duas dimensões representa o aspecto chave para se alcançar a vantagem competitiva. Souza e Rocha (2009, p. 34) afirmam que a análise da cadeia de valor das empresas tem como principal objetivo:

[...] conquistar e manter vantagens competitivas, detectando oportunidades, ameaças, pontos fortes e pontos fracos, fontes de diferenciação comparadas com cadeias concorrentes e gerar ideias para ganhos de produtividade, lucratividade e rentabilidade para a empresa e para o segmento da cadeia.

Para que a empresa possa ser eficaz no atual ambiente competitivo, ela deverá estender seu comportamento integrado para incorporar clientes e fornecedores, pois visualizar apenas as operações internas isoladamente não é mais suficiente para que a empresa possa alcançar seus objetivos (BOWERSOX; CLOSS, 1996).

\subsubsection{Análise do posicionamento estratégico}

O posicionamento estratégico das empresas é um dos pontos chave no que diz respeito ao sucesso empresarial, pois as empresas deverão verificar qual é seu posicionamento no mercado em relação aos seus concorrentes. Tal análise terá como intuito verificar as oportunidades oferecidas pelo ambiente externo, os recursos existentes, a definição de metas e de planos de ação para alcançá-las. Neste contexto, a rápida adequação do sistema de controle gerencial possui papel relevante, pois às rápidas mudanças no ambiente de negócios exige uma rápida mudança nos sistemas de controle. De acordo com Gomes e Salas (2001, p. 109): 
Gestão estratégica de custos: Estudos de casos de empresas industriais do setor de construção naval localizadas no estado do Rio de Janeiro Helmut Alexandre De Paula, Josir Simeone Gomes

Um sistema deve adequar-se às características do contexto social e, como consequência, à estratégia da empresa. O sistema de controle deve estar estreitamente relacionado com o processo estratégico, contribuindo tanto na formulação de alternativas estratégicas como no processo posterior da implantação dessa alternativa para facilitar a congruência da atuação dos administradores e das diferentes unidades com as diretrizes globais.

Para Silva (1999, p. 19), a definição de posicionamento estratégico "é importante para que os agentes econômicos classifiquem qual o objetivo que deve ser perseguido por todos os agentes para alcançar competitividade".

Dentro do contexto competitivo onde as relações empresariais ocorrem, surgi a necessidade de as organizações adotarem um posicionamento estratégico misto, que de acordo com Gomes e Salas (2001, p. 110) é:

[...] a forte competitividade obriga a ter estratégias que combinam tanto a diferenciação como a liderança em custos. A necessidade de se dispor de um nível elevado de excelência operacional (custos, produtividade, flexibilidade, tempo de processo e entrega) combinada com uma suficiente diferenciação obriga as empresas a combinarem as características estratégicas [...].

A análise do posicionamento estratégico busca relacionar a empresa com seu ambiente, principalmente nas organizações que competem no mesmo setor, para tomar ações ofensivas ou defensivas e, desta forma, enfrentar com êxito as forças competitivas. Shank e Govindarajam (1997, p. 148) mencionam que "[...] a estratégia de uma unidade de negócios pode ser considerada ao longo de duas dimensões: sua missão (construir, manter, colher) e sua vantagem competitiva (baixo custo, diferenciação). Esta estrutura permite-nos considerar de forma explícita 0 posicionamento estratégico [...]".

O posicionamento estratégico é a chave para criar e sustentar vantagem competitiva. "Uma vantagem competitiva é a criação de um valor melhor para o cliente por um custo igual, ou mais baixo, àquele oferecido pelos competidores, ou a criação de um valor equivalente por um custo menor do que aquele oferecido pelos 
Gestão estratégica de custos: Estudos de casos de empresas industriais do setor de construção naval localizadas no estado do Rio de Janeiro Helmut Alexandre De Paula, Josir Simeone Gomes

competidores" (HANSEN; MOWEN, 2003, p. 423). E os autores afirmam que: "o posicionamento estratégico é o processo de seleção da combinação ótima das três abordagens estratégicas gerais. A combinação é selecionada com o objetivo de criar vantagem competitiva sustentável". As estratégias gerais que os autores comentam são: A liderança em custos; Diferenciação e a Focalização ou Enfoque. $O$ conhecimento prévio da estratégia a ser adotada pelas organizações é uma condição básica para o sucesso empresarial (GARRISON; NOREEN; BREWER, 2007).

\subsubsection{Análise dos determinantes de custos}

$\mathrm{Na}$ análise dos direcionadores/determinantes de custos sabe-se "[...] que o custo é causado, ou direcionado, por muitos fatores que se inter-relacionam de formas complexas" (SHANK; GOVINDARAJAN, 1997, p. 21). Para Blocker et al. (2008, p. 55) "[...] direcionador de custos é qualquer fator que tem o efeito de mudar o nível do custo total. " Já Nakagawa (1991, p. 81) faz o seguinte comentário: "[...] ao mesmo tempo que mecanismos de desagregação de custos são utilizados, também, para a descoberta da relação de causa e efeito na incoerência de custos [...]".

No processo de gestão estratégica de custos, a análise de direcionadores de custos representa um fator importante para o desenvolvimento e formulação de estratégias competitivas (DIENG, 2005, p.66).

Assim, no enfoque da GEC, os determinantes (direcionadores) de custos correspondem às escolhas estratégicas e operacionais que a organização entende como a forma mais adequada para executar suas operações (PARISI; MEGLIORINI, 2011). Os autores ainda mencionam que os determinantes de custos podem ser: a) determinantes de custos baseados em atividades; b) determinantes de custos baseados em volume e c) determinantes de custos baseados em estrutura e execução. "Observar apenas o relacionamento dos custos com o volume produzido é perder a riqueza da análise do comportamento dos custos" (MAUSES et al. 2006, p. 4). Correa e Caon (2002, p. 202) fazem o seguinte comentário: "[...] apesar de algumas empresas estarem preocupadas com a gestão dos seus custos, a maioria continua considerando o volume de produção como a causa que melhor explica a variação dos custos [...]." 
Gestão estratégica de custos: Estudos de casos de empresas industriais do setor de construção naval localizadas no estado do Rio de Janeiro Helmut Alexandre De Paula, Josir Simeone Gomes

As medidas usadas para atribuir ou designar custos das atividades para outros objetos de custeio, como produtos em nível individual, são conhecidas como direcionadores de custos de atividades (BLOCKER et al., 2008).

Percebe-se que os determinantes de custos das atividades compreendem os parâmetros que serviram de base para apropriação dos custos aos produtos ou serviços. Isso permite à empresa um gerenciamento das atividades que agregam valor e a eliminação daquelas desnecessárias, fazendo com que a apuração dos custos seja mais precisa, além de possibilitar aos gestores que se ocupem mais com as atividades que mais consomem recursos, o ABC e o ABM têm essa função (PARISI; MEGLIORINI, 2011).

\subsection{Métodos de custeio}

A contabilidade de custos possui diferentes maneiras de atribuir valores aos produtos fabricados e aos serviços prestados. Essas diferentes maneiras de atribuição de custos são denominadas métodos ou metodologia de custeio. De acordo com Silva et al. (2002, p. 2), "os métodos de custeio mais usuais: o Custeio Pleno, o Custeio por Absorção, O Custeio Variável e o Custeio ABC (Activity Based Costing)".

No método de custeio por absorção tanto os custos diretos como os indiretos fazem parte da composição do custo do produto ou serviços prestados (LUNKES, 2004; MARTINS, 2001). O custeio por absorção possui três passos para sua apuração, conforme afirma Crepaldi (2011, p. 84):

O custeio é um processo de três passos. Primeiro, é preciso separar os custos de produto do custo do período. Segundo, os custos diretos do produto são atribuídos aos produtos específicos, enquanto os custos indiretos são atribuídos a centros de custos. Terceiro, os custos indiretos são distribuídos do centro aos produtos de acordo com seu uso.

Outro método para se custear um produto ou serviço é o custeio variável. O custeio variável só considera como custo de produção aqueles que variam de acordo com o volume de produção, que normalmente são: a matéria-prima, a mão-de-obra 
Gestão estratégica de custos: Estudos de casos de empresas industriais do setor de construção naval localizadas no estado do Rio de Janeiro Helmut Alexandre De Paula, Josir Simeone Gomes

direta e a parcela variável dos custos gerais de fabricação. Os custos fixos de produção são tratados como custos do período, ou seja, é o mesmo tratamento dado às despesas, que são lançadas integralmente contra a receita em cada período. Assim, o custo de uma unidade produzida em estoque ou no custo do produto vendido, no método do custeio variável, não contém qualquer custo fixo de produção.

O custeio baseado em atividades $(A B C)$ é uma metodologia que objetiva aumentar a acurácia da mensuração dos custos dos produtos, assim como da performance na utilização dos recursos e na realização das atividades. Essa metodologia de apuração de custos vem sendo implementada com sucesso em diversos países no mundo (BHIMANI et al., 2007).

Para Hansen e Mowen (2003, p.392), o "sistema de custeio baseado em atividades $(A B C)$, primeiramente rastreia os custos para as atividades e, em seguida, para os produtos e outros objetos de custo". Assim, o custeio baseado em atividades está fundamentado no princípio de que as atividades consomem recursos, enquanto os produtos consomem atividades e materiais. O custeio de um produto ou serviço é aprimorado por uma identificação mais específica dos custos de suporte, que pelos métodos tradicionais são classificados como custos gerais de fabricação e rateados aos produtos. O custo do produto por atividade é calculado pela identificação dos materiais e atividades necessárias para fabricar o produto ou prestar o serviço e da quantidade das atividades para cada produto ou serviço (NAKAGAWA, 2007).

$O$ custeio baseado em atividades utiliza os cost-drives (geradores/condutores de custos) para definição do custo unitário de uma atividade. Entende-se como gerador/condutor de custo o evento relacionado a uma ou mais atividades, que provoca sua ocorrência, como por exemplo o número de setups, número de ordens de compra, número de clientes, entre outros.

Para Porter (1992, p. 58), "condutores de custos são os determinantes estruturais do custo de uma atividade e diferem de acordo com o controle que uma empresa exerce sobre eles. Eles determinam o comportamento dos custos dentro de uma atividade, refletindo quaisquer elos ou inter-relações que os afetam". Exemplos: economias de escala, aprendizagem, o padrão de utilização da capacidade, elos, inter- 
Gestão estratégica de custos: Estudos de casos de empresas industriais do setor de construção naval localizadas no estado do Rio de Janeiro Helmut Alexandre De Paula, Josir Simeone Gomes

relações, integração, momento oportuno, políticas discricionárias, localização e fatores institucionais.

Para Nakagawa (2007, p. 30), "o ABC tem como objetivo facilitar a mudança de atitude dos gestores de uma empresa, a fim de que estes, paralelamente à otimização de lucros para os investidores, busquem também a otimização do valor dos produtos para os clientes (internos e externos) ". Desta forma, o custeio baseado em atividades constitui uma importante ferramenta estratégica que permite ao gestor adicionar valor à empresa.

Maher (2001, p. 294) apresenta duas formas em que o custeio baseado em atividade adiciona valor às companhias:

a) Melhores informações sobre custos de produtos que ajudam os administradores a tomar decisões sobre preços de vendas, sobre manter ou eliminar produtos. Os administradores também utilizam informações sobre custos para decidir se continuam vendendo certos produtos.

b) Melhores informações sobre custos das atividades e processos que ajudam os administradores a implantar medidas de redução de custos.

O custeio baseado em atividades funciona como um regulador do uso de recursos nas empresas, pois o monitoramento constante das atividades proporcionado pelo seu uso auxilia na detecção do mau uso de recursos. Assim, os gerentes das atividades têm um incentivo para manter suas operações competitivas pela identificação contínua dos geradores de desperdício. $\mathrm{O} A B C$ é uma ferramenta poderosa para administrar a operação complexa de um negócio através da avaliação detalhada das atividades, ele atribui dados de custos e desempenho às atividades. Desta forma, a administração dispõe de informações sobre os custos e desempenho das atividades, além de determinar o custo do produto de forma correta, melhora o processo de negócio, elimina desperdícios (atividades que não agregam valor), identifica os geradores de custos, contribui para o planejamento das operações e também ajuda a estabelecer as estratégias do negócio (BRIMSOM, 1996). 
Gestão estratégica de custos: Estudos de casos de empresas industriais do setor de construção naval localizadas no estado do Rio de Janeiro Helmut Alexandre De Paula, Josir Simeone Gomes

Percebe-se nitidamente que $\mathrm{A} A B C$ contribui sobremaneira para a gestão estratégica de custos, uma vez que ele possibilita o monitoramento de todas as atividades desenvolvidas pela empresa e, com isso, se tem condições de identificar aquelas que não estão agregando valor e eliminá-las.

Com o intuito de fixar preços, surgiu na Alemanha no início do século XX a ideia do RKW (Reichskuratorium fur Wirtschaflichtkeit), que consiste na alocação de custos e despesas aos produtos fabricados ou serviços prestados. Para Martins (2001, p. 220), "Com fundamento na ideia do uso de custos para fixar preços nasceu, no início do século $X X$, uma forma de alocação de custos e despesas muitíssimo conhecida no nosso meio brasileiro por RKW [...]". Nesta metodologia, se aloca "[...] aos produtos e serviços todos os custos e despesas, inclusive as financeiras, fornecendo dessa maneira o montante total gasto pela empresa no esforço completo de obter receita" (CREPALDI, 2011, p. 263). No método RKW/Pleno a empresa é dividida em centros de custos e estes recebem os custos e despesas por meio de bases de distribuição e posteriormente aos produtos ou serviços por meio de critério de utilização desses recursos (BEUREN; SCHLINDWEIN, 2008).

\section{METODOLOGIA DO ESTUDO}

A elaboração de um trabalho científico requer do pesquisador o estabelecimento de uma forma/maneira de como será elaborada a pesquisa, desta forma, ele deverá seguir com rigor os processos que irá utilizar em sua investigação, assim, o "[...] método científico é o conjunto de processos ou operações mentais que se devem empregar na investigação" (SILVA, 2001, p.25). Goldenberg (1999), afirma que "[...] a metodologia é o estudo dos caminhos a serem seguidos, dos instrumentos usados para ciência". Assim, a elaboração desta de pesquisa, foi feita mediante a consideração das etapas necessárias ao seu desenvolvimento e que estão representadas na Figura 1. 
Gestão estratégica de custos: Estudos de casos de empresas industriais do setor de construção naval localizadas no estado do Rio de Janeiro Helmut Alexandre De Paula, Josir Simeone Gomes

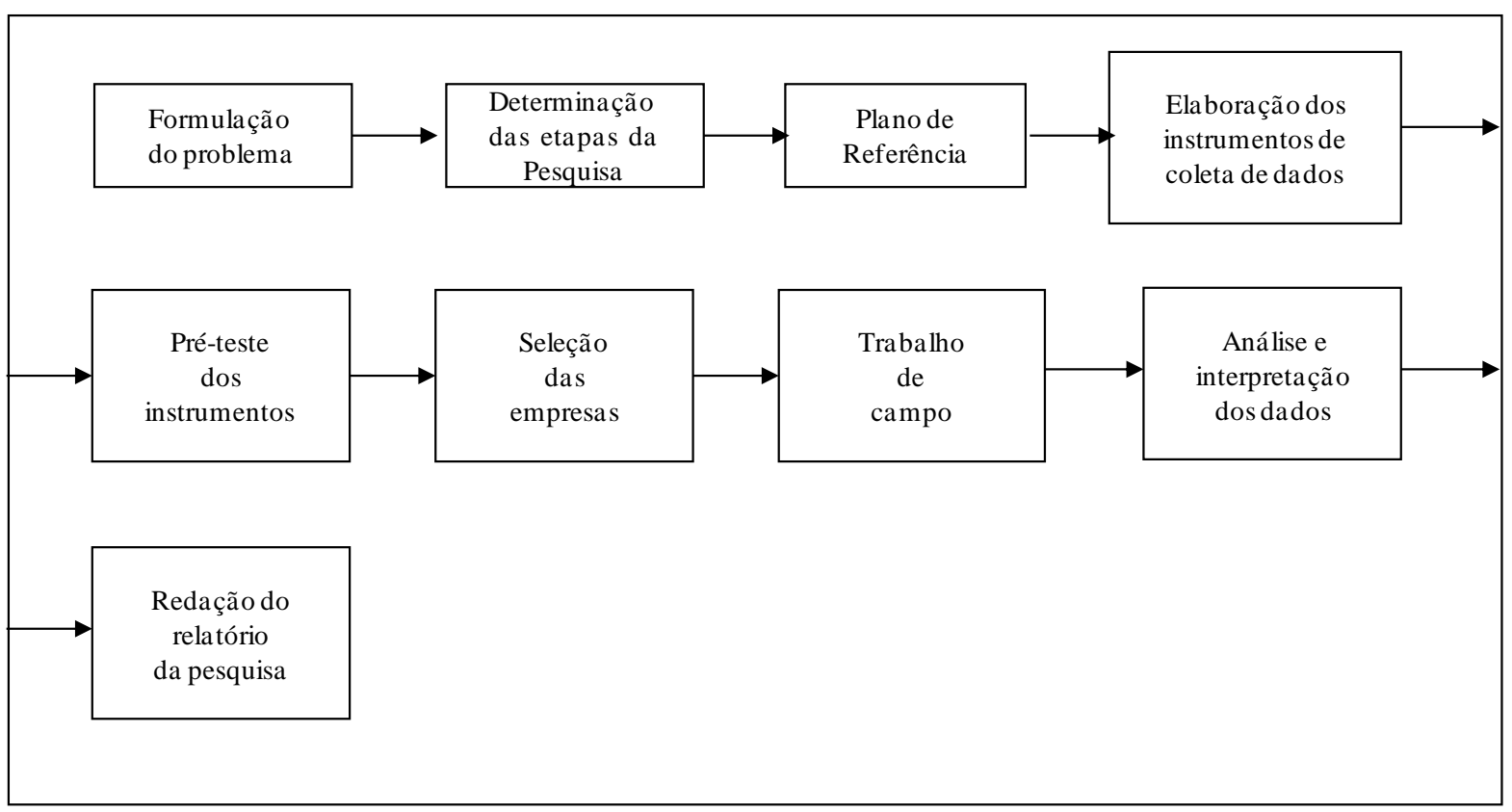

Figura 1 - Etapas do processo de pesquisa

Fonte: Adaptada Gil (2002, p. 21).

Para a realização da pesquisa foram utilizados Estudos de Casos. De acordo com Collis e Hussey (2005, p. 72),

Um estudo de caso é um exame extensivo de um único exemplo de um fenômeno de interesse. Envolve reunir informações detalhadas sobre a unidade de análise, geralmente durante um período muito longo, tendo em vista obter um conhecimento aprofundado.

Para Gil (2007, p. 54), o estudo de caso "consiste no estudo profundo e exaustivo de um ou poucos objetos, de maneira que permita seu amplo e detalhado conhecimento [...]". Yin (2005) afirma que a pesquisa que se utiliza de casos múltiplos é mais consistente e permite maiores generalizações, mas, no entanto, demandam maiores recursos e tempo por parte do pesquisador.

As empresas que constituem a indústria de construção naval do Estado do Rio de Janeiro, de acordo com o SINAVAL, totalizam onze empresas. Assim, o estudo pesquisou cinco empresas, constituindo uma amostra não probabilista ou por acessibilidade. 
Gestão estratégica de custos: Estudos de casos de empresas industriais do setor de construção naval localizadas no estado do Rio de Janeiro Helmut Alexandre De Paula, Josir Simeone Gomes

Os dados obtidos no estudo foram coletados pessoalmente pelo pesquisador, através da aplicação de questionário. Com intuito de facilitar a análise e interpretação dos dados o questionário foi dividido em três blocos, o primeiro se destinou a coletar os dados relativos as características gerais das empresas estudadas, o segundo teve como objetivo identificar as características dos sistemas de custos e o terceiro de verificar quais os instrumentos que são utilizados para a gestão estratégica de custos.

Devido ao compromisso assumido com os entrevistados, procurou-se disfarçar os dados apresentados nos tópicos que tratam das características das empresas estudadas, de modo a dificultar a identificação das empresas. Assim, as empresas serão identificadas por códigos alfabéticos de $A$ a $E$, e suas características principais serão apresentadas sem as especificações, que pudessem facilitar a identificação das mesmas.

\section{ANÁLISE DOS RESULTADOS}

As cinco empresas estudadas na pesquisa atuam no segmento de construção naval (construção de embarcações), e são privadas, ou seja, o estudo não levou em consideração empresas do mesmo segmento do setor público. As empresas estudadas, além de pertencerem ao mesmo segmento, possuem diversas características semelhantes, cabendo destacar que: todas são empresas de grande porte, sua constituição societária é sob a forma de sociedade por ações, possuem em seus quadros funcionais números superiores a 500 funcionários, o faturamento anual é superior a $\mathrm{R} \$ 60$ milhões. Já com relação à cidade onde estão localizadas, as empresas A, B, C e D encontram-se estabelecidas na cidade de Niterói e a empresa E está situada na cidade do Rio de Janeiro. 
Gestão estratégica de custos: Estudos de casos de empresas industriais do setor de construção naval localizadas no estado do Rio de Janeiro Helmut Alexandre De Paula, Josir Simeone Gomes

\begin{tabular}{|c|c|c|c|c|c|c|c|c|}
\hline Empresa & $\begin{array}{c}\text { Sistema de } \\
\text { acumulação }\end{array}$ & $\begin{array}{c}\text { Método de } \\
\text { custeio }\end{array}$ & $\begin{array}{l}\text { Sistema } \\
\text { integrado }\end{array}$ & $\begin{array}{c}\text { Rateio dos } \\
\text { gastos indiretos }\end{array}$ & $\begin{array}{l}\text { Controle de } \\
\text { custos }\end{array}$ & $\begin{array}{c}\text { Avaliação de } \\
\text { desempenho } \\
\text { com base nos } \\
\text { custos } \\
\end{array}$ & $\begin{array}{c}\text { Gastos que } \\
\text { recebem maior } \\
\text { atenção no } \\
\text { processo produtivo }\end{array}$ & $\begin{array}{c}\text { Relatórios } \\
\text { de custos }\end{array}$ \\
\hline $\mathrm{A}$ & Por ordem & Pleno & Parcialmente & $\mathrm{HH} *$ & Orçamento & Sim & MOD ** & Planilhas \\
\hline $\mathrm{B}$ & Por ordem & Absorção & Parcialmente & $\mathrm{HH} *$ & Orçamento & Não & MOD ** & Planilhas \\
\hline $\mathrm{C}$ & Por ordem & Absorção & Totalmente & $\mathrm{HH} *$ & Orçamento & Não & $\begin{array}{c}\text { Materiais importados } \\
\text { aço }\end{array}$ & Planilhas \\
\hline $\mathrm{D}$ & Por ordem & \begin{tabular}{|l|} 
Pleno \\
\end{tabular} & Totalmente & $\mathrm{HH} *$ & Orçamento & Não & MOD ** & SIG \\
\hline $\mathrm{E}$ & Por ordem & Pleno & Parcialmente & $\mathrm{HH}^{*}$ & Orçamento & Sim & MOD ** & Planilhas \\
\hline
\end{tabular}

* Homem Hora

** Mão-de-obra direta

Quadro 1 - características dos sistemas de custos Fonte: Dados da pesquisa

É possível, a partir do Quadro 1, perceber que nas empresas estudadas os sistemas de acumulação de custos, as bases de rateio dos gastos indiretos de fabricação e controle de custos, possuem características similares. Já os demais componentes do sistema de custos, quando não idênticos estão próximos uns dos outros.

Os sistemas de custos existentes nas empresas que constituem a indústria de construção naval do Estado do Rio de Janeiro, que fizeram parte desta pesquisa, apresentaram características semelhantes em sua forma e estrutura, porém contrariando o que é preconizado por Shank e Govindarajam (1997), não fazem uso de uma importante ferramenta que é mais adequada ao cenário competitivo atual que é o custeio baseado em atividades ( $A B C)$. Assim, a não utilização do $A B C$ prejudica a interpretação das informações geradas pelos sistemas de custos das empresas pesquisadas.

Outro problema identificado na pesquisa foi à falta de integração do sistema de custos com outros sistemas existentes nas empresas, pois apenas duas delas possuem um sistema totalmente integrado enquanto as demais possuem apenas parte do sistema integrado, acarretando muitas vezes em perda de informação, demora na elaboração dos relatórios, além de gastos adicionais com mão-de-obra para compilar as informações não integradas. Neste sentido, Alves, Alves et al. (2000), comentam que um grande obstáculo na gestão de custos é a falta de informações integradas. 
Gestão estratégica de custos: Estudos de casos de empresas industriais do setor de construção naval localizadas no estado do Rio de Janeiro Helmut Alexandre De Paula, Josir Simeone Gomes

No que diz respeito aos objetivos estratégicos, na empresa $A$ os objetivos $e$ metas estratégicas são elaborados pelos diretores e gerentes dos departamentos, na B participam do estabelecimento os gerentes, superintendentes e supervisores, na $C$ são os diretores e acionistas os responsáveis pela elaboração das metas, nas $D$ e $E$ as metas são fixadas pela diretoria seguindo as orientações do controlador.

Nas cinco empresas estudadas, dentro do rol de metas e objetivos estratégicos estão presente em todas às empresas, questões relacionadas à redução de custos além de outros.

\begin{tabular}{|c|l|l|c|c|c|}
\hline Empresa & \multicolumn{1}{|c|}{$\begin{array}{c}\text { Relacionamento } \\
\text { comFornecedores }\end{array}$} & \multicolumn{1}{|c|}{$\begin{array}{c}\text { Relacionamento } \\
\text { com Clientes }\end{array}$} & $\begin{array}{c}\text { Acompanhamento } \\
\text { processos internos }\end{array}$ & $\begin{array}{c}\text { Posicionamento } \\
\text { estratégico }\end{array}$ & $\begin{array}{c}\text { Direcionadores } \\
\text { de custos }\end{array}$ \\
\hline A & Poucos fornecedores & Diretoria comercial & Sim & Diferenciação & HH* \\
\hline B & Diversos fornecedores & Relações com clientes & Sim & Liderança em custos & HH* \\
\hline C & $\begin{array}{l}\text { Poucos fornecedores } \\
\text { prazo de entrega e qualidade }\end{array}$ & $\begin{array}{l}\text { Não possui um departamento } \\
\text { que trate exclusivamente do } \\
\text { relacionamento comclientes }\end{array}$ & Sim & Mista & HH* \\
\hline D & $\begin{array}{l}\text { Poucos fornecedores } \\
\text { contratos de fornecimento }\end{array}$ & Relações com clientes & Sim & Liderança emcustos & HH* \\
\hline E & $\begin{array}{l}\text { Poucos fornecedores } \\
\text { contratos de fornecimento } \\
\text { prazo de entrega e qualidade }\end{array}$ & Departamento comercial & & \\
\hline
\end{tabular}

* Homem Hora

\section{Quadro 2 - Gestão estratégica de custos}

Fonte: Dados da pesquisa

Observou-se nas empresas estudadas que as metas e objetivos estratégicos estão direcionados a ações que visam à redução de custos.

$\mathrm{Na}$ empresa $\mathrm{A}$, os objetivos e metas estratégicas são elaborados pelos diretores e gerentes dos departamentos. $\mathrm{Na}$ empresa $\mathrm{B}$, participam do estabelecimento os gerentes, superintendentes e supervisores, e na $C$ são os diretores e acionistas os responsáveis pela elaboração das metas. Nas empresas $D$ e $E$, as metas são fixadas pela diretoria seguindo as orientações do controlador.

Todos os entrevistados afirmam ter alcançado as metas estabelecidas nos últimos três anos. Após estabelecidas as metas e objetivos, as cinco empresas fazem a divulgação por meio de reuniões com seus funcionários. A empresa $B$, além das reuniões, também realiza a divulgação por meio de boletins internos. 
Gestão estratégica de custos: Estudos de casos de empresas industriais do setor de construção naval localizadas no estado do Rio de Janeiro Helmut Alexandre De Paula, Josir Simeone Gomes

O Quadro 3 apresenta o processo de elaboração das metas estratégicas das empresas estudadas.

\begin{tabular}{|c|l|l|l|l|}
\hline Empresa & \multicolumn{1}{|c|}{$\begin{array}{c}\text { Estabelecimento } \\
\text { das metas }\end{array}$} & $\begin{array}{l}\text { Metas de } \\
\text { redução de } \\
\text { cus tos }\end{array}$ & $\begin{array}{l}\text { Divulgação } \\
\text { das metas }\end{array}$ & $\begin{array}{l}\text { Alcance das } \\
\text { metas nos } \\
\text { últimos 3 anos }\end{array}$ \\
\hline A & Diretoria e Gerências & Sim & Reuniões & Sim \\
\hline B & $\begin{array}{l}\text { Diretoria, Gerência, } \\
\text { Supervisão e Supervisão }\end{array}$ & Sim & $\begin{array}{l}\text { Reuniões e } \\
\text { boletins internos }\end{array}$ & Sim \\
\hline C & Acionis tas e Diretoria & Sim & Reuniões & Sim \\
\hline D & Diretoria & Sim & Reuniões & Sim \\
\hline E & Diretoria & Sim & Reuniões & Sim \\
\hline
\end{tabular}

Quadro 3 - Metas estratégicas

Fonte: Dados da pesquisa

Dentro da cadeia de valores das empresas estudas, observa-se que as empresa A, C, D e E adotam políticas de trabalhar com poucos fornecedores para materiais específicos o que é condizente com a visão de Hansen e Mowen (2003), que ao optarse em trabalhar com um número pequeno de fornecedores a organização consegue exigir um nível de qualidade, que garante a produção de produtos com um menor nível de defeitos.

Apenas a empresa B adota políticas de trabalhar com diversos fornecedores, apesar disso, desenvolve um trabalho de estabelecer uma relação de proximidade com os fornecedores que, de acordo com Shank e Govindarajam (1997), é uma estratégia que traz benefícios para as empresas que a utilizam.

Ainda, no que diz respeito ao relacionamento com fornecedores, as empresas $D$ e $\mathrm{E}$ possuem contratos com alguns de seus fornecedores que garantem um patamar de fornecimento mínimo o que resulta em um valor de aquisição menor, colaborando com a estratégia de redução de custos na aquisição de insumos (HANSEN; MOWEN, 2003). Warren, Reeve e Fess (2008, p. 437), chamam os contratos de longo prazo com os fornecedores de parceria com fornecedores e, enfatizam que tais parcerias "[...] encorajam os fornecedores a se comprometerem com o fabricante, para que a qualidade dos materiais comprados seja alta, o custo baixo e a entrega pontual". 
Gestão estratégica de custos: Estudos de casos de empresas industriais do setor de construção naval localizadas no estado do Rio de Janeiro Helmut Alexandre De Paula, Josir Simeone Gomes

As empresas $\mathrm{C}$ e $\mathrm{D}$ exigem dos fornecedores o cumprimento rigoroso nos prazos de entrega bem com a garantia da qualidade desses insumos e, na mesma linha Parisi e Megliorini (2011) afirmam que a exploração das relações com fornecedores por parte da empresa que adquire os insumos é uma alternativa eficaz para redução de custos e aumento na qualidade dos produtos.

O relacionamento com clientes nas empresas $B$ e $D$ é realizado pelo departamento de relações com clientes. Na empresa E, é realizado pelo departamento comercial que cuida da prospecção dos negócios e atende aos clientes. Na empresa $\mathrm{C}$, por possuir um único cliente, não existe um departamento que cuide do relacionamento com cliente, apesar da organização manter uma relação de proximidade com o mesmo. Por último, a empresa $A$ faz o trabalho de relacionamento com os clientes por meio de sua diretoria comercial.

Apesar das empresas utilizarem estratégias competitivas diferentes, todas as empresas estudadas mostraram-se comprometidas com o estabelecimento de metas de redução de custos, pois acreditam que obter patamares de custos abaixo dos principais concorrentes, pode trazer vantagem no mercado altamente competitivo.

Das cinco empresas estudadas, apenas a empresa A não possui um departamento que cuida dos processos internos. Porém, na referida empresa está sendo realizado, por uma empresa de consultoria, um trabalho que possui como objetivo mapear todos os processos existentes, após isto, serão sugeridas melhorias para alguns processos e a eliminação de outros.

Os departamentos existentes nas empresas possuem o mesmo foco que é o acompanhamento das atividades desenvolvidas em seus processos produtivos, visando executá-los da melhor maneira possível, ganhado com isso, agilidade na produção e garantindo a execução das tarefas da melhor forma possível.

Com relação à GEC, a pesquisa constatou que as empresas dão uma atenção especial aos eventos ocorridos dentro da cadeia de valor, ainda no que se refere à cadeia de valor os processos ganham uma atenção especial, pois todas as empresas possuem o mesmo foco que é o acompanhamento das atividades desenvolvidas em seus processos produtivos, visando executá-los da melhor maneira possível, ganhado 
Gestão estratégica de custos: Estudos de casos de empresas industriais do setor de construção naval localizadas no estado do Rio de Janeiro Helmut Alexandre De Paula, Josir Simeone Gomes

com isso, agilidade na produção e garantindo a execução das tarefas da melhor forma possível. Para Shank e Govindarajam (1997), controlar e conhecer os processos possibilita as empresas eliminar atividades que não agregam valor ao produto e, como consequência ocorre à redução de custos. A atenção aos processos internos é uma preocupação constante das organizações, isso foi o que constatou o estudo realizado por Kaspczak (2008) em 49 empresas do segmento metal-mecânico.

\section{CONSIDERAÇÕES FINAIS}

Dado ao questionamento estabelecido para este estudo, de responder qual a relação, em termos de proximidade ou afastamento, existente entre a prática da indústria de construção naval do Estado do Rio de Janeiro e a literatura sobre gestão estratégica de custos, conclui-se que as respostas foram obtidas. A seguir são feitas algumas considerações a respeito dos achados da pesquisa.

Apesar das empresas não utilizarem o ABC, o estudo constatou a existência de um rigoroso controle de custos que é realizado através do orçamento. O monitoramento constante dos custos visa assegurar a rentabilidade desejada pelas empresas, uma vez que os preços dos produtos são estabelecidos com base no custo projetado e, qualquer desvio pode comprometer as margens de lucro das empresas. Nessa mesma ótica, Batista e Werner (2004) comentam que o controle de custos é essencial para se obter bons resultados e o orçamento tem sido uma das ferramentas mais utilizadas para este controle.

Constatou-se, que as empresas estudadas dão uma maior atenção aos eventos ocorridos na cadeia de valor, ou seja, no relacionamento com fornecedores e clientes, e também na análise de seus processos internos, o que está em conformidade com os estudos realizados por Carr e Tomkins (1996) e Kaspczak (2008), que observaram que as empresas se preocupam com seus processos internos, pois acreditam que o monitoramento contínuo possibilita evitar desperdícios, além de otimizar a utilização da mão-de-obra. 
Gestão estratégica de custos: Estudos de casos de empresas industriais do setor de construção naval localizadas no estado do Rio de Janeiro Helmut Alexandre De Paula, Josir Simeone Gomes

Lord (1996) em seu estudo constatou que a exploração das ligações dentro da cadeia de valor proporciona vantagem competitiva. Ainda no que diz respeito às transações ocorridas na cadeia de valor, duas das empresas estudadas trabalham com contratos de longo prazo, junto a seus principais fornecedores, o que as proporcionam reduções nos custos de aquisição de seus insumos, colaborando com a estratégia de liderança em custos.

Empresas dos mais diversos segmentos têm mostrado que adotar estratégias que visam a liderança em custos pode ser a chave para sair de situações de crise é o que comprovou Miotto (2007), em estudo realizado em empresas de aviação comercial ao comentar que uma das empresas estudadas, após mudar a sua estratégia para a de liderança em custos foi possível reverter a situação de seguidos prejuízos para uma situação de lucro.

Cabe também mencionar, que às empresas estudadas utilizam algum tipo de ferramenta de gestão empresarial que possui papel de grande relevância na GEC, tais ferramentas são: custo-meta, ISO 9000, treinamento das equipes de produção, JIT e qualidade total. Esta constatação também foi feita por Kaspczak (2008) em seu estudo realizado em 49 empresas do setor metal-mecânico.

A GEC possibilita uma análise de custos mais ampla, pois não se limita apenas a conhecer o custo de produção, a preocupação agora é de se conhecer os custos ao longo de toda a cadeia de valor assim, a análise é ampliada e as possibilidades de redução de custos são aumentadas e este aumento das possibilidades contribui para estratégia de liderança em custos.

Foi observado que as empresas não fazem uso de uma importante ferramenta que auxilia a gestão de custos que é o ABC. Conhecer os motivos/causas da sua não utilização se constitui em um importante assunto para pesquisas futuras.

Outra constatação feita na pesquisa foi a utilização de um único critério de rateio para a alocação dos gastos gerais de fabricação e, que de acordo com Martins (2001), a utilização de um mesmo critério para rateio de custos que possuem diferentes direcionadores, aumenta o subjetivismo na alocação dos custos, causando distorções 
Gestão estratégica de custos: Estudos de casos de empresas industriais do setor de construção naval localizadas no estado do Rio de Janeiro Helmut Alexandre De Paula, Josir Simeone Gomes

no custo final dos produtos. Assim, a investigação dos motivos que levam as empresas a empregar esta prática é uma interessante problemática a ser pesquisada.

\section{REFERÊNCIAS}

AGUIAR, A. B.; MARTINS, G. A. (2006). A teoria das estruturas organizacionais de Mintzberg e a gestão estratégica de custos: um estudo nas ONGs paulistas. Revista Contabilidade e Finanças da USP. São Paulo, Edição comemorativa, p. 51-64, set.

ALVES, M. H. F.; LAMOUNIER, A. E. B.; JABUR, F. P. (2000). Internet - adicionando valor por meio de inovações descontinuadas: a experiência brasileira. Revista de Administração FGV. São Paulo, v. 35, n. 2, p. 30-36, abr./jun.

ARAÚJO, A. O. (2001). Contribuição ao estudo de indicadores de desempenho de empreendimentos hoteleiros. 171 p. (Tese de Doutorado). Faculdade de Economia, Administração e Contabilidade, Universidade de São Paulo, São Paulo.

BATISTA, A. A.; WERNER, I. A. (2004). Gestão de custos nas empresas de comércio e serviços. In: CONGRESSO BRASILEIRO DE CUSTOS, 11. Bahia. Anais... Bahia.

BEUREN, I. M.; SCHLINDWEIN, N. F. (2008). Uso do custeio por absorção e do sistema RKW para gerar informações gerenciais: um estudo de caso em hospital. ABCustos, Associação Brasileira de Custos. v. 3, n. 2, mai./ago.

BHIMANI, Alnoor; GOSSELIN, Maurice; NCUBE, Mthuli; OKANO, Hiroshi. (2007). Activity-Based Costing: How far have we come internationally? Cost Management. v. 21, n. 3, p. 12-17, May/Jun.

BOWERSOX, D. J.; CLOSS, D.J. (1996). Logistical management: the integrated supply chain process. New York: McGraw-Hill.

BLOCKER, E. J.; CHEN, K. H.; COKINS, G.; LIN, T. W. (2008). Cost management: a strategic emphasis. 4. ed. Ney York: McGraw-Hill.

BRIMSON, James A. (1996). Contabilidade por atividades: uma abordagem de custeio baseado em atividades. São Paulo: Atlas.

CADEZ, S.; GUILDING, C. (2008). An exploratory investigation of an integrated contingency model of strategic management accounting. Accounting, Organizations and Society, v. 33, p. 836-863, Jan. 
Gestão estratégica de custos: Estudos de casos de empresas industriais do setor de construção naval localizadas no estado do Rio de Janeiro Helmut Alexandre De Paula, Josir Simeone Gomes

CARR, C.; TOMKINS, C. (1996). Strategic investment decisions: the importance of SCM. A comparative analysis of 51 case studies in U.K., U.S. and German companies. Management Accounting Research, n. 7, p. 199-217.

CORRÊA, Henrique L.; CAON, Maurício. (2002). Gestão de serviços: lucratividade por meio de operações e de satisfação de clientes. São Paulo: Atlas.

COLLIS, Jill; HUSSEY, Roger. (2005). Pesquisa em Administração - Um guia para alunos de graduação e pós-graduação. 2. ed. Porto Alegre: Bookman.

CREPALDI, Silvio A. (2011). Contabilidade Gerencial: teoria e prática. 5. ed. São Paulo: Atlas.

DIEHL, C. A.; GONÇALO, C. R. (2005). Gestão estratégica de custos: Uma estrutura para análise da estratégia praticada aplicada em empresas de serviços. In: CONGRESSO INTERNACIONAL DE CUSTOS, 9., 2005. Florianópolis. Anais...Florianópolis.

GARRISON, Ray, H.; NOREEN, Erick, W.; BREWER, Peter, C. (2007). Contabilidade Gerencial. 11. ed. Rio de Janeiro: LTC.

GIL, Antonio, C. (2007). Como Elaborar Projetos de Pesquisas. 4. ed. São Paulo: Atlas.

GOLDENBERG, M. (1999). A arte de pesquisar: como fazer pesquisa qualitativa em Ciências Sociais. Rio de Janeiro: Record.

GOMES, J. S.; SALAS, J. M. A. (2001). Controle de gestão: uma abordagem contextual e organizacional. 3. ed. São Paulo: Atlas.

HANSEN, Don R., MOWEN, Maryanne M. (2003). Gestão de Custos. São Paulo: Pioneira Thomson Learning.

KASPCZAK, Márcia C. M. (2008). Gestão estratégica de custos: um estudo empírico no segmento metal-mecânico. Paraná. 2008. 125 p. (Dissertação de Mestrado). Programa de Pós-Graduação em Engenharia de Produção, Universidade Tecnológica Federal do Paraná, Paraná.

LORD, B. R. (1996). Strategic management accounting: the emperor's new clothes? Management Accounting Research, n. 7, p. 347-366.

LUNKES, Rogério J. (2004). Manual de Contabilidade Hoteleira. São Paulo: Atlas.

MAHER, M. (2001). Contabilidade de custos: criando valor para a administração. São Paulo: Atlas. 
Gestão estratégica de custos: Estudos de casos de empresas industriais do setor de construção naval localizadas no estado do Rio de Janeiro Helmut Alexandre De Paula, Josir Simeone Gomes

MARTINS, E. (2001). Contabilidade de custos. São Paulo: Atlas, 9. ed.

MAUSES, C. S.; SOUZA, M. A.; MAGALHÃES, J. M. (2006). A gestão estratégica de custos como instrumento de redução do trade-off entre o custo e diferenciação, baseada na flexibilidade. In: CONGRESSO BRASILEIRO DE CUSTOS, 12., 2006, Belo Horizonte. Anais...Belo Horizonte.

MIOTTO, G. R. (2007). Análise da gestão estratégica de custos no setor de aviação comercial brasileiro. 2007. 167 p. Dissertação de Mestrado. Programa de PósGraduação em Ciências Contábeis, Universidade do Vale do Rio dos Sinos, São Leopoldo.

NAKAGAWA, Masayuki. (1991). Gestão Estratégica de Custos: conceito, sistemas e implementação. 1. ed. São Paulo: Atlas.

Atlas.

. (2007). ABC Custeio Baseado em Atividades. 2. ed. 5. reimpr. São Paulo:

PARISI, Cláudio; MEGLIORINI, Evandir. (2011). Contabilidade Gerencial. São Paulo: Atlas.

POMPERMAYER, C. B. (2004). A influência de fatores organizacionais nos aspectos práticos dos sistemas de gestão de custos. 2004. 254 p. (Tese de Doutorado). Programa de Pós-Graduação em Engenharia de Produção, Universidade Federal de Santa Catarina, Santa Catarina.

PORTER, M. E. (1992). Vantagem competitiva. Rio de Janeiro: Campus. . (2004). Estratégia competitiva. Rio de Janeiro: Elsevier.

QUESADO, Patrícia, R.; RODRIGUES, Lúcia, L. (2005). A Gestão Estratégica de Custos em Portugal: Uma Análise Exploratória. In: CONGRESSO INTERNACIONAL DE CUSTOS, 9., 2005. Florianópolis. Anais...Florianópolis.

REIS, M. H. V.; REIS, R. P.; REIS, A. J. dos. (1998). Competitividade do leite no Mercosul: o caso de Minas Gerias e Argentina. Cadernos de Administração Rural, Lavras, v. 10, n. 1, p. 65-70, jan./jun.

ROSLLENDER, R.; HART, S. J. (2003). In search of strategic management accounting: theoretical and field perspectives. Management Accounting Research, v. 14, p. 255 257.

SHANK, J.K; GOVINDARAJAN, V. (1997). A Revolução dos Custos: como reinventar e redefinir sua estratégia de custos para vencer em mercados crescentemente competitivos. 3. ed. Rio de Janeiro: Campus. 
Gestão estratégica de custos: Estudos de casos de empresas industriais do setor de construção naval localizadas no estado do Rio de Janeiro Helmut Alexandre De Paula, Josir Simeone Gomes

SILVA, C. L. (1999). Gestão estratégica de custos: o custo meta na cadeia de valor. Revista FAE, Curitiba, v. 2, n. 2, p.17-26, mai./ago.

SILVA, E. L. MENEZES, E. M. (2001). Metodologia da pesquisa e elaboração de dissertação. 3. ed. Florianópolis: Laboratório de Ensino a Distância da UFSC.

SILVA, Ana P. F; MIRANDA, Luiz C.; FALK, James A. (2002). Estudo dos métodos de custeio mais utilizados pelos hospitais de Recife. In: CONGRESSO BRASILEIRO DE CUSTOS, 9., 2002, São Paulo. Anais...São Paulo.

SOUZA, Bruno; ROCHA, Welington. (2009). Gestão de Custos Interorganizacionais: ações coordenadas entre clientes e fornecedores para otimizar resultados. São Paulo: Atlas.

WARREN, Carl S.; REEVE, James M.; FESS, Philip E. (2008). Contabilidade Gerencial. 2. ed. São Paulo: Thomson Learning.

YIN. R. K. (2005). Estudo de caso: planejamento e métodos. 3 ed. Porto Alegre: Bookman.

Data de Submissão: 22/01/2012

Data de Aceite: 15/03/2016 